\title{
AC 2008-968: PATHWAYS TO LEARNING: ORCHESTRATING THE ROLE OF SUSTAINABILITY IN ENGINEERING EDUCATION
}

Richard Theis, Embry-Riddle Aeronautical University, Prescott

patricia watkins, Embry-Riddle Aeronautical University Library

MLIS, Research and Reference Instruction Librarian

Mary Angela Beck, Embry-Riddle Aeronautical University

Assistant Professor of Humanities and Communications 


\title{
Pathways to Learning: Orchestrating the Role of Sustainability in Engineering Education
}

\begin{abstract}
The 2001 Action Plan put forth by the American Society of Civil Engineers (ASCE) articulates the "principles of sustainable development"1 as primary to the ASCE's code of ethics to be implemented in engineering education. Previously, in June of 1999, the Board of Directors for the American Society for Engineering Education (ASEE) approved the following statement on sustainable development in education:

Engineering students should learn about sustainable development and sustainability in the general education component of the curriculum as they are preparing for the major design experience. ... Engineering faculty should use system approaches, including interdisciplinary teams, to teach pollution prevention techniques, life cycle analysis, industry ecology, and other sustainable engineering concepts. ${ }^{2}$
\end{abstract}

ASEE has aligned this statement with the program outcomes for ABET Criteria 3 which include the following ${ }^{3}$ :

3c) An ability to design a system, component, or process to meet desired needs within realistic constraints such as economic, environmental, social, political, ethical, health and safety, manufacturability and sustainability;

3f) An understanding of professional and ethical responsibility; and

3h) The broad education necessary to understand the impact of engineering solutions in a global and societal context.

Thus, integrating the theory and practice of sustainability into a curriculum is a critical issue for engineering educators to address. We seek to examine how best to insert these criteria of sustainability into our unique university context so as to better meet the educational objectives mandated by ABET.

We are an undergraduate technical university in the American Southwest offering degrees in aeronautical sciences, global security and intelligence, space physics, and aerospace, mechanical, electrical, and computer engineering. If our educators are to initiate sustainability into these programs, we must first examine pathways to learning and how best to introduce sustainability to the campus and curriculum.

Pathways to learning include not only transmission of information in set course curriculum but also speaker forums, inter-school partnerships, textbooks, study abroad, capstone design 
programs, internships, field trips and other opportunities that create real-world learning. Such pathways are also generated through collaborative partnerships between faculty and library staff.

\section{Introduction}

We are university educators who are not engineers but who frequently collaborate with our engineering colleagues in the development of content, materials, and teaching strategies. These collaborations are designed to support our students' general education skills within their engineering courses. One critical general education topic that may not be integrated into engineering courses at technical universities such as ours is sustainability.

Sustainability is specifically addressed by ABET Criteria 3c which states that students should gain "an ability to design a system, component, or process to meet desired needs within realistic constraints such as economic, environmental, social, political, ethical, health and safety, manufacturability and sustainability ${ }^{3}$." According to the ASEE, "In teaching sustainable design, faculty should ask their students to consider the impacts of design upon U.S. society, and upon other nations and cultures. ... using systems approaches, including interdisciplinary teams, to teach pollution prevention techniques, life cycle analysis, industrial ecology, and other sustainable engineering concepts ${ }^{4}$ ". Thus, sustainability is a critical topic for us to consider as we continually improve our engineering curriculum.

After reviewing the ABET standards, we determined that as a future-oriented university valuing the worth of sustainability education, we must evaluate engineering courses to see how sustainability might be most effectively or most creatively introduced into the current engineering curriculum, i.e., what the most effective pathways of learning might be. However, engaging in such a project requires a rigorous self-reflection process by all the stakeholdersfaculty, staff, students, administrators-to successfully implement such curricular changes. Assessment of stakeholder attitudes is therefore critical to a study such as this.

This paper will report on a research project that will: 1) extend the idea of collaborative education to include library staff, communications staff, and other critical stakeholders to explore an orchestral approach that might increase the number of pathways to learning available to our campus community, 2) survey university stakeholders (top administrators, staff, faculty, students) to discover what has been done to date regarding the sustainability issue in their education and to uncover what might be done to further implement this approach successfully, and 3) examine how best to insert sustainability into the present engineering curriculum at our university. To accomplish these goals, we propose qualitative surveys and interviews.

The following section briefly argues for sustainability in engineering education and is followed by a brief description of this study's research context. Details of the qualitative methods for collecting and analyzing data, results of this research, and suggestions for integrating this vital component into the general engineering curriculum at our university are also presented in the Methods/Data Collection section. Throughout this paper the collaborative nature of curricular change is stressed. 


\section{Sustainability in Engineering}

On June 24, 2002, at their national conference in Washington, D.C., the National Academy of Engineering made the following declaration:

Creating a sustainable world that provides a safe, secure, healthy life for all peoples is a priority for the U.S. engineering community. It is evident that the U.S. engineering community must increase its focus on sharing and disseminating information, knowledge and technology that provides access to minerals, materials, energy, water, food and public health while addressing basic human needs. Engineers must deliver solutions that are technically viable, commercially feasible, and environmentally and socially sustainable. ${ }^{5}$

Clearly, sustainability education will play a major role in providing society with engineers who are environmentally conscious and critically aware of the global engineering challenges present in our society today and for the future. However, after a review of syllabi and course descriptions, it is apparent that few courses at our university integrate sustainability or ecology in the engineering program.

Typically, undergraduate engineering students might wait until graduate school to study in-depth the newer concepts of sustainability; however, we believe that the concept of sustainability should be introduced early into the school's engineering program. Students might then benefit from an ongoing immersion beginning in their very first year and going through their senior year of study. This immersion would evolve into a sustainable engineering education that might involve internships, team design experiences or field studies, capstone projects, and real-world experiences. In addition, other benefits would accrue:

- Real world skills and attitudes that reflect the importance of sustainability in engineering;

- A critical awareness of the emerging new role for the contemporary engineer in society and the world; and

- An evolving, critical, and professional self-reflection for envisioning future environments.

However, will administration, faculty, and staff at our university be amenable to the introduction of sustainability in their courses and into the curriculum? What do students want in their education and courses that address sustainability? How might critical resources, such as our library staff, aid us in curricular development? What might be the most effective pathways to learning sustainability in our particular university context?

To answer these questions, we approached the entire engineering community, from students to library staff. We believe that community is built on both consensus and dissensus- that both are necessary to conducting an analysis that gets at the core issues in creating and planning such a dramatic change in the engineering programs at our university. Consequently, the research methods presented here allow for stakeholder disagreement as regards curricular content and 
modification. To give the reader a better understanding of the stakeholders in this study, the following section outlines our research context.

\section{Research Context}

We are a 4-year university in the Southwest United States with an enrollment of approximately 1,600 undergraduate students. The most popular degree programs at this university are Aeronautical Science, Aerospace Engineering, and other types of engineering-Computer Engineering, Electrical Engineering, and Mechanical Engineering. The College of Engineering houses a college dean, an associate dean, 25 full-time faculty, 3 adjunct faculty, 5 staff members, and approximately 500 engineering majors. These students typically take courses such as "Engineering Materials Science with Laboratory," "Solid Mechanics," "Experimental Aerodynamics," "Structures," "Space Mechanics," and "Spacecraft Detail Design." A strong emphasis on laboratory and design work prepares students for their senior capstone design courses, and the engineering faculty stresses an applied, "hands-on" approach to learning.

Along with general engineering courses such as "Introduction to Engineering" and various math and science courses, typical core requirements for the engineering programs at our university include general education courses such as "Engineering and Society," "Introduction to Geography," and "Values and Ethics." As potential pathways to learning, these courses provide unique opportunities for sustainability education. Various minor fields of study may also provide effective pathways to learning: the minor in Aerospace Life Studies requires courses such as "Human Performance and Extreme Environments," "Principles of Ecology," and "Environmental Compliance." The minor in Applied Meteorology requires the study of "Applied Climatology," "Weather for Aircrews," and "Satellite and Radar Weather Interpretations." Sustainability could readily be integrated into any of these courses as a primary or secondary course topic.

Sustainability has also been included as a topic for instruction by librarians in various research courses. Several "Technical Writing" courses have been taught in the library during the past year that required engineering students to research and find articles on the topics of sustainability and green building design. Librarians conducted over 70 instruction classes for students in 2007 on the topics of research design and location and citation of scholarly articles. Three subject bibliographic and instruction librarians are also actively involved in the collection of library resources necessary for learning and research in conjunction with class syllabi: books, scholarly journals, and article databases. The library staff also includes a Director, an Associate Director for Collection Development, an Electronic Resources Librarian, an Archives/Special Collections Librarian and 3 staff involved in administration, cataloging, and serials collection. The library at our university, then, is an integral partner in coordination with engineering and other faculty to provide student instruction and research using library resources.

Before any specific pathways to learning could be identified and assessed, however, we had to determine the attitudes of university stakeholders regarding sustainability in engineering education. The following section outlines our methodology for a research study that examines these attitudes and analyzes the results of our data collection for incorporating sustainability into the engineering curriculum. 


\section{Methods/Data Collection}

We are interviewing primary stakeholders about their attitudes and practices towards sustainability in our engineering curriculum. Research results will help define and design methods to aid in the promotion of sustainable development in our school's curricula not only to meet ABET criteria, but to better educate and prepare students for sustainable engineering practice in a global environment. We also hope to expand upon the following results from informal surveys conducted among students in two "Technical Writing" classes in Fall 2006 that found that although specific terms of sustainability - durability, cost to the environment, and global warming-were recognized by students, they displayed little understanding of how sustainability is incorporated into their engineering studies.

By interviewing engineering faculty about how they currently approach the topic of sustainability in their courses and how they might envision integrating sustainability in future classes, we hope to begin shaping a future curriculum and policy that embraces the emerging societal and technological needs for sustainability in engineering education.

Following standard methods of qualitative research design ${ }^{6}$, we constructed an interview instrument as the primary tool for this study. This instrument includes a) a written definition of sustainability, and b) a list of questions which are being posed to specific stakeholders at this university. The interview questions and the stakeholders targeted by each interview question are listed below:

\section{Administrators}

1. Has the administration given any thought to a policy of a "sustainable campus" that addresses issues of energy conservation, sustainability and making the campus more "environmentally-friendly"? Please describe. What might be some attributes of a "sustainable campus"?

2. How might you envision the integration of sustainability into the current engineering curriculum? Has the administration given any thought to including sustainability education as a central part of the curricula? Why or Why not?

3. How might the university engage in cross-functional or cross-institutional efforts that promote sustainability in education? Who might be some of the stakeholders in such an effort?

4. What kind of overall policy does the university have in place to encourage "green" curriculum development?

5. What kind of "green initiatives" has the university launched to encourage recycling, environmental sustainability?

6. Does the university have any plans to create "teach-ins," conferences or community discussions to address the issues of climate change, alternative fuels, 
human rights, food in the future, reducing our carbon footprint, personal consumption and production? Why or why not?

\section{Faculty}

1. What does the word "sustainability" mean to you?

2. Have you incorporated issues of sustainability into the curriculum/courses here on campus? If yes, please describe. If no, why not?

3. How might you incorporate topics of sustainability into the degree/class/curriculum you are involved in?

4. What other kinds of experiences might be helpful for you or your students on the topic of sustainability in your field of study?

5. What kinds of sustainability topics might you employ for research in your classes? Are there specific research or study materials to employ for study?

\section{Librarians}

1. How does the library collect information that supports the topic of sustainability in the library?

2. Has the topic of sustainability, climate change, or other environmental topics been included as a topic for research in instruction classes for students?

3. What kinds of media, books or other materials are actively being collected on the topic of sustainability across the curriculum in the university?

\section{Staff}

1. What does the word "Sustainability" mean to you?

2. What other words or ideas come to mind when I say "sustainability" or "engineering sustainability"?

3. How has the issue of sustainability or other environmental factors been addressed at ERAU?

4. What experiences have you been involved in on campus that have incorporated sustainability or other environmental issues?

5. What kinds of sustainability topics might you like to see incorporated into the ERAU campus community? 


\section{Students}

1. What does the word "Sustainability" mean to you?

2. What types of design projects, internships or field studies would you consider that incorporates topics of environmentalism or sustainability?

3. What other words or ideas come to mind when I say "sustainability" or "engineering sustainability"?

4. How has the issue of sustainability or other environmental factors been addressed in your classes here at ERAU?

5. What fieldwork or other experiences have you been involved in that incorporated sustainability or other environmental issues in your studies?

6. What kinds of sustainability topics might you like to see incorporated into your studies?

Seven interviews were conducted through the email questionnaire method (Survey Respondents: 4 librarians, 2 students, 1 staff) and personal interviews (Interviewees: 2 College Deans, 4 faculty). Prior to the personal interviews (45 minutes - 60 minutes in duration), administrators and faculty received a printed copy of the survey. All interviews were conducted individually with 2-3 interviewers and the respondent in the room. One interview was conducted by 3 interviewers with 2 respondents. Interviewers took detailed notes, later transcribing these notes for data analysis and potential follow-up interviews. Once collection of interview data is complete, the responses were reviewed, categorized, and collated. We specifically noted responses that point to specific pathways to learning that might be utilized in our university context. We also specifically noted any challenges to the integration of sustainability in the general engineering course curriculum.

The responses of our library staff are noteworthy. By including them in this curricular conversation, we hope to extend the idea of collaborative education to include library staff, communications staff, and other critical stakeholders as we explore an orchestral approach that might increase the number of pathways to learning available to our campus community.

Research results will help define and design methods to aid in the promotion of sustainable development in our school's curricula not only to meet ABET criteria, but to better educate and prepare students for sustainable engineering practice in a global environment. Through this qualitative study, we hope to begin shaping a future curriculum and policy that embraces the emerging societal and technological needs for sustainability in engineering education. 


\section{Interview Results}

\section{Historical Context}

ERAU/Prescott is a 4-year university in Northern Arizona with an enrollment of approximately 1,700 undergraduate students. The most popular engineering degree program is Aerospace Engineering (AE). Students majoring in AE take typical AE courses such as Engineering Materials Science with Laboratory, Solid Mechanics, Experimental Aerodynamics, Space Mechanics, Aerodynamics and Structures. There is a strong emphasis on laboratory and design work to prepare the students for the senior capstone design courses.

Several years ago new directions were charted for the campus with the introduction of several new bachelors' degree programs, including Aviation Environmental Science (AES). The AES degree is the only undergraduate Environmental Science degree program in North America with an aviation and aerospace focus. It is anticipated that graduates of this program will be prepared to tackle environmental and safety issues in the aviation and aerospace industries. As such, the inception of this new program marks ERAU's burgeoning interest in all things "green", including sustainability.

In analyzing the results of the surveys and interviews discussed in the previous section, we have identified several critical conversational threads that deserve highlighting as they indicate our respondents' views on sustainability in ERAU's engineering curriculum and thus mark potential pathways to learning.

\section{Thread 1: Sustainability is a new concept to ERAU's educational mission.}

Sustainability is just beginning to be touched on in Aviation Environmental Science (AES) and in courses such as Technical Report Writing and Ethics and Values. In Physical Science 142 (AES), according to one faculty member, "students do their Senior Thesis on topics related to sustainability." In addition, AES students have the opportunity to concentrate their studies in either "Applied Environmental Science" or "Environmental Management."

Core courses in AES program include Introduction to Environmental Sciences, Principles of Ecology, Environmental Consulting, and Environmental Law. In addition, required courses in the students' area of concentration include Environmental Chemistry, Air Quality and Sound Pollution, and Environmental Compliance and Safety. Finally, possible designated electives might include Riparian Ecology, Consumer and Hazardous Waste, Atmospheric Environmental Studies, and Water Quality.

In the Technical Report Writing course, sustainability and the environment/green buildings were used as topics for research in a library instruction. According to one librarian, "As Engineering liaison librarian for the university, I routinely scan book and other media catalogs in the engineering disciplines to find books and other media on the issue of sustainability."

Philosophically, all stakeholders appear to struggle, in part, with a definition of sustainability as do the researchers collecting and reflecting on the interviews. As Patricia Watkins, ERAU 
Research Librarian, who completed the interview questions for librarians and is also a participating researcher notes, "the concept appears to be schizophrenic in nature-pertaining to the green movement/ecology of the planet or the idea of sustainability relating to the carbon footprint and durability of materials for the next generation." As the Dean of the College of Engineering remarks, "eco and green might mean that the engineering processes you use increase or decrease the footprint [and] how to prevent or put measures in place to avoid pollution ... how to create and use a system along the way that has a smaller impact on the environment."

Although many faculty members appear to be well-grounded in a theoretical knowledge of sustainability, many wonder how to incorporate sustainability into their classes. In particular, one Aeronautical Engineering faculty member argues: "For many topics in engineering, it is a bit of a stretch to incorporate directly into our analysis in our courses." He also notes: "My area of scholarship — orbital debris - is certainly related to sustainability, but we don't focus much on sustainability." Another faculty member focuses on the micro-course creation; that is, he understands the macro-applications of sustainability, but, as he say, "For the university, issues like bio fuels and nuclear fusion are really important topics, but again not for a [computer] microprocessor class."

As a new concept at ERAU, our challenge is to conduct additional research to investigate practical pathways of learning about sustainability and where these pathways lie-links between engineering and general education has been one logical avenue. Both faculty and administration have offered suggestions that a course in the ethics of sustainability might be a beginning. One administrator notes, "Topics for aerospace sustainability might involve issues of what to do with the toxic chemicals in our airplanes or what to do with the chemicals in satellites."

\section{Thread 2: Sustainability is important but not a core part of ERAU's educational mission.}

Responses to the survey and in-depth interviews indicate that faculty agree that sustainability is an important concept for engineering students to understand and that these students should be familiar with the concept (ABET 2000). Indeed, the notion of sustainability is touched upon in several general engineering courses across all four years of study, including the final capstone senior design courses.

However, few instructors claimed that they themselves included sustainability as a core component in their course plans, either because the course topic did not lend itself to the subject (i.e., courses in computer programming) or because the instructor felt that the subject might be more easily incorporated into other courses, including non-engineering, general education courses. One suggestion was for humanities and social science professors to introduce an elective course in sustainability that would teach students how design practices can help profitability while simultaneously protecting the planet, i.e., recycling heavy metals rather than mining them. Indeed, one course offered at ERAU that might benefit from this approach and thus provide a pathway to learning is Economics for Engineers.

Another interview response that ties to this thread was that education continues outside of university and that the university cannot and should not be responsible for an individual's entire education. The workplace itself is a critical learning environment; as our Dean of the College of 
Engineering stressed, industry actually teaches some things much better than colleges do, and one of these things is sustainability. In school, students learn design, finite elements, statics, and computational fluid dynamics. They get a broad-brush approach to education. In industry, however, students learn how to be part of a profitable corporate culture. In doing so, they become specialized in project management, quality assurance, and perhaps sustainability. The university's mission is to introduce the concept and help students learn how to embrace it, but it is industry's mission to teach their new employees how to practice sustainability within the specific corporate culture.

\section{Thread 3: Sustainability is gaining popularity as a cultural phenomenon, especially among our staff and students.}

Efforts at ERAU to address sustainability have begun in earnest. In particular, the Resource Conservation Coalition (RC2), comprised of students, faculty, and staff, have volunteered to be involved in addressing sustainability issues on campus. According to the Chair of the RC2, "Each campus group seeks to reduce campus use of valuable resources, raise community awareness and understanding of environmental issues and the responsibilities each person has to help address these issues." She adds: "These issues include investigating campus energy requirements (solar energy), conservation, alternative fuel vehicle fleet, and the campus commitment to build a Leadership in Environmental and Energy Design (LEED) building."

Few students responded to our interview questionnaire. However, one student mentions that while the topic of sustainability is not widely discussed in her classes, she is aware of the concept: "While writing articles, I have encountered new aircraft such as Spaceship Two that use much less fuel than traditional aircraft. I have also become fascinated with the Boeing 787 which also uses much less fuel, but these haven't really come up in any classes. You only have to turn on the news or read a little aviation or engineering news to have these things in your face, but I haven't really seen anything in my classes." This student expresses clear ideas about her limitations and strengths in knowledge about sustainability. While she does not experience much about environmental issues, she is very articulate about the topic and how she would like to see it incorporated into the curriculum.

\section{Challenges}

Awareness of sustainability is low among campus stakeholders at this point in time. Awareness falls into two categories: 1) Lack of awareness about the topic or 2) how sustainability fits into current curriculum that might include the basic concepts of durability, recycling, reduction of carbon footprint, energy usage, alternative energy sources, and other concepts that are being discussed now in the media and global thought leaders.

What issues might be incorporated in the future:

1. What is industry asking us to do;

2. how do we teach sustainability concepts in the manufacture of products and design; and 
3. how do we learn the culture in industry and companies for how they expect students to be prepared for jobs that incorporate sustainability.

Although the concept of sustainability in the engineering curriculum is understood and appreciated, faculty, students, and staff are tasked with navigating new pathways of learning. Ultimately, the challenge for creating new knowledge pathways falls on all stakeholdersstudents, staff, faculty, and administrators. Research at the university will continue as we examine and develop new programs, curriculum, and inter-school partnerships in the life-long learning project of sustainability education.

\section{References}

${ }^{1}$ American Society of Civil Engineers (ASCE). Action Plan 2001: Building ASCE's Future. www.asce.org/pdf/actionplan2001.pdf, 2001.

${ }^{2}$ American Society for Engineering Education (ASEE). ASEE Board of Directors Statement on Sustainable Development Education. http://asee.org/about/Sustainable_Development.cfm, 1999.

${ }^{3}$ Accreditation Board for Engineering and Technology (ABET) Accreditation Commission. Criteria for Accrediting Engineering Programs: Effective for Evaluations During the 2008-2009 Cycle. Baltimore: ABET, 2007.

${ }^{4}$ American Society for Engineering Education (ASEE). ASEE Statement on Sustainable Development Education,, retrieved from http://www.asee.org/about/Sustainable_Development.cfm.

${ }^{5}$ American Society of Civil Engineers (ASCE). Sustainable Engineering Practice: An Introduction. Reston, VA: ASCE, 2004.

${ }^{6}$ Marshall, Catherine and Gretchen Rossman. Designing Qualitative Research. ( ${ }^{\text {th }}$ Edition). Thousand Oaks, CA: Sage, 2006. 